\title{
Theoretical investigation of friction forces between vane tip and cam-ring in oil vane pumps
}

\author{
Mohamed Elashmawy ${ }^{1,2}$ \\ ${ }^{1}$ Mechanical Engineering Department, Engineering College, University of Hail, Hail, Saudi Arabia \\ ${ }^{2}$ Engineering Science Department, Faculty of Petroleum and Mining Engineering, Suez University, Suez, Egypt
}

\section{Email address:}

arafat_696@yahoo.com

\section{To cite this article:}

Mohamed Elashmawy. Theoretical Investigation of Friction Forces between Vane Tip and Cam-Ring in Oil Vane Pumps. International Journal of Science, Technology and Society. Vol. 2, No. 5, 2014, pp. 121-128. doi: 10.11648/j.ijsts.20140205.15

\begin{abstract}
Oil type used for oil vane pumps is an essential element affecting its performance. Trying to understand oil type effect and proper oil type selection will lead to significant enhancement of oil pump performance and increase its life time. In order to accomplish this task, a simple thermo-elasto-hydrodynamic lubrication (TEHL) model was used to calculate the friction forces between vane tip and cam-ring. Effect of oil temperature, vane relative speed, normal vane force, and oil film thickness were theoretically investigated for different oil types. Navier-Stokes and energy equations were numerically solved using finite difference technique. Viscosity and density distributions as a function of oil pressure and temperature were taken into consideration. Results show that proper oil type selection and its operating temperature are key parameters that significantly affecting the vane pump performance. The vane relative speed is quit important parameter affecting the coefficient of friction and should not be less than $5 \mathrm{~m} / \mathrm{s}$. increasing of lubricant film thickness is not necessarily enhances the friction coefficient between van tip and cam-ring. The study shows that the best type of oil for vane pump in some operating conditions is not necessarily the best choice for this pump in other operating conditions. It may be helpful for designers to select more than one oil type for the same pump according to its operating conditions.
\end{abstract}

Keywords: Vane pump, Friction, Friction coefficient, TEHL, Oil type, Vane tip, Film thickness, Oil temperature

\section{Introduction}

Friction force between vane tip and cam-ring is relatively high compared to other tribological friction sources in a vane pump. Trying to understand the nature and behavior of such friction is very important to minimize it. Decreasing vane tip friction enhances vane pump performance which enhances pump life time and its fuel consumption. Thermo-elasto-hydrodynamic lubrication (TEHL) model was developed. Theoretical results showed good agreement with the experimental results $[1,2]$. Numerous parameters affecting the vane pump performance was theoretically and experimentally studied by others. The following parameters were selected:

\subsection{Vane Geometry}

A computer model was developed using a mixed lubrication model to investigate tribological performance of blade and liner interface in a transfer pump lubricated with diesel fuel. Results show that increasing blade surface radius greatly improves the film parameter and reduces the interfacial friction by $80 \%$ [3]. Suitable contact force of the vane tip along with proper system geometry, are essential on enhancing the efficiency and long life of the pump. Three different vane tip geometries were theoretically studied using CAD and CFD modeling, Fig. 1. Results show that the best solution would be a profile with radiused inlet of the vane tip (decreases turbulence) and with NACA investigated profile in the outlet of the vane tip. This allows obtaining relatively small leakages and small blade forces [4].

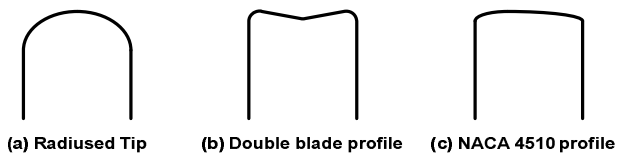

Figure 1. The three deferent vane tip geometries [4].

Effect of vane thickness parameter on a balanced vane pump performance was investigated. Although increasing of vane thickness increases the friction force between 
cam-ring and vane tip, the pump efficiency did not decrease by increasing vane thickness. The important parameter affecting the balanced vane pump efficiency is the ratio of vane pump lift to the vane thickness $(\varepsilon)$. Reducing friction coefficient and increasing $\varepsilon$ would result in increasing of the pump efficiency [5]. Recently an experimental and theoretical study about $\varepsilon$ effect on vane tip friction torque of the vane pump was performed. Results show that increasing of $\varepsilon$ increases the variation of the vane friction torque [6].

\subsection{Surface Roughness of the Cam}

Film thickness at the blade-liner interface in a transfer pump lubricated with diesel fuel is generally lower than the surface roughness level. Reducing the surface roughness has a significant effect on improving film thickness-to-surface roughness ratio [3]. Friction torque due to the friction between vane tip and cam contour is significant. The friction torque was reduced by lessening the surface roughness of the cam contour, which improves pump mechanical efficiency [7].

\subsection{Coatings}

Ion-plated hard and wear-resistant TiN coatings were applied and tested within vane pumps. A factor of 400 of wear reduction for the coated parts was obtained. The uncoated counterparts showed a decrease in wear by a factor of 60 [8]. A comparison was performed between five different Physical Vapor Deposition (PVD) coated vane tips and the normal vane without coating. The results show that the effect of the normal vane force and the pressure difference between the two sides of the vane were very small compared to the relative speed of the vane tip. Coating material shows low effect on enhancing the friction coefficient between vane tip and cam-ring in oil vane pumps [2].

\subsection{Oil Temperature}

Navier- Stokes and energy equations were numerically solved using finite difference technique. Viscosity and velocity distribution were calculated for both thermal and isothermal TEHL models and a comparison between them was performed. Isothermal TEHL model means that the temperature distribution in the study area is not considered and all taken as constant equal to pump oil temperature. The results show that the temperature has a great effect on oil viscosity and velocity distribution which indicate that isothermal analysis is highly not recommended for the applications and parameters that depend on viscosity and/or velocity distributions [1]. Increasing oil temperature decreases friction force and enhances vane pump efficiency in low temperature regions. However in high temperature regions friction forces would not decrease and correspondingly the efficiency would not increase by increasing the temperature [9]. Overall efficiency of an internal gear and balanced vane pumps decreases at extremely low and high oil temperatures. Oil temperature region of around $80^{\circ} \mathrm{C}$ is the region with a higher overall pump efficiency [10].

In the present study the friction force between vane tip and cam-ring is theoretically investigated. A simple TEHL-model [1] was used. Validation of the TEHL-model was tested using the experimental results [2]. The effect of some parameters on the friction coefficient was studied. Operating oil temperature, relative speed between vane tip and cam-ring, normal vane force and oil film thickness are the parameters in focus of this study. These parameters were investigated for 3 different oil groups to predict the effect of oil type on van pump performance. This will help vane pump designers to enhance the vane pump performance.

\section{Simulation and Modeling of Smooth Contact between Vane Tip and Cam-Ring}

Tribological contact between vane tip and cam-ring is theoretically investigated using TEHL-model assuming the contact is smooth. With this assumption the material roughness engagement in the friction forces will not be considered and only friction forces due to oil fluid is engaged. Further efforts are needed in the field of engagement of material effects on the TEHL-model to enable theoretical study of mixed friction. The material engagement is beyond the scope of this study.

\subsection{Pressure Distribution and Film Thickness}

Fig. 2 shows a comparison between Hertzian pressure distribution and the common theoretical models solving Reynolds equation with elastic deformation. In the TEHL-model, the contact zone geometry is simplified by assuming the contact surfaces to be parallel. This assumption will significantly simplify the model. With this approximation Reynolds equation (1) and deformation equation (2) will not be considered. Fig. 13 (appendix 2) shows more geometry details and exact dimensions used for the TEHL-model.

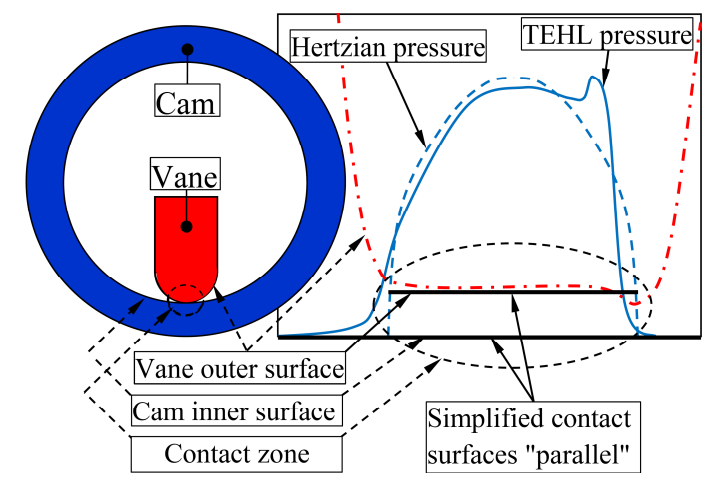

Figure 2. Comparison between typical and approximated pressure and film thickness distribution. 


$$
\begin{gathered}
\frac{d P}{d x}=12 \mu u\left(\frac{h(x)-h_{o}}{h(x)^{3}}\right) \\
h(x)=h_{\text {min }}+\frac{x^{2}}{2 R}-\frac{2\left(1-v^{2}\right)}{\pi E} \int_{-\infty}^{\infty} P(s) \ln (x-s)^{2} d s
\end{gathered}
$$

The concept of TEHL-model is to use Hertz theory to predict the pressure distribution "elliptic curve" (7), Fig. 2, and using Hamrock-Dowson formula to predict the lubricant mean film thickness, (8) [11].

$$
\begin{gathered}
P_{H}=\sqrt{\frac{F E^{\prime}}{2 \pi R l_{\text {eff }}}} \\
b_{H}=\sqrt{\frac{8 F R}{\pi E^{\prime} l_{\text {eff }}}} \\
E=\frac{2 E_{1} E_{2}}{E_{1}+E_{2}} \\
E^{\prime}=\frac{E}{\left(1-v^{2}\right)}, \quad v=0.3 \\
P(x)=P_{H} \sqrt{1-\left(\frac{x}{b_{H}}\right)^{2}} \\
h_{O}=2.69 G^{0.53} U^{0.67} W^{-0.067} R
\end{gathered}
$$

Where G: Material parameter, U: Speed parameter, W: Load parameter and R: Reduced radius of curvature.

$$
\begin{gathered}
G=\alpha_{p} E^{\prime} \\
U=\frac{\mu_{o} u}{2 E^{\prime} R} \\
W=\frac{F}{E^{\prime} R l_{\text {eff }}}=2 \pi\left(\frac{P_{H}}{E^{\prime}}\right)^{2} \\
R=\frac{R_{1} R_{2}}{R_{1}+R_{2}}
\end{gathered}
$$

\subsection{Velocity Distribution within Lubricant Film}

Navier-Stokes equation, (13) is used to calculate the velocity distribution within the lubricant film of the smooth contact between vane tip and cam-ring.

$$
\frac{\partial P}{\partial x}=\mu\left(\frac{\partial^{2} u}{\partial y^{2}}\right)+\frac{\partial \mu}{\partial y}\left(\frac{\partial u}{\partial y}\right)
$$

Equation (13) is solved under certain conditions: 1- steady flow, 2- two-dimensional flow in $\mathrm{x}$ and $\mathrm{y}$ directions, velocity in $\mathrm{y}$ direction is considerably smaller than in the $\mathrm{x}$ direction $(v<<u), 3$ - the gradients of the first and higher order of velocity in $\mathrm{x}$ direction is considerably smaller than in the $\mathrm{y}$ direction, and 4- the pressure change in $y$ direction is extremely insignificant.

\subsection{Temperature Distribution within Lubricant Film}

Energy equation in its simple two dimensional form, (14) is used to calculate the temperature distribution within the lubricant oil film. The specific heat of oil was taken as $c_{p}=2000 \mathrm{~J} / \mathrm{kgK}$. The upper and lower boundaries are the surface temperatures of vane tip and cam-ring. Wall temperatures were assumed to be constant and equal to the oil temperature $\left(\mathrm{T}_{\mathrm{o}}\right)$. Conduction heat transfer coefficient for oil was taken according to Rodermund (16).

$$
\begin{array}{r}
{ }_{-} \rho c_{p}\left(u \frac{\partial T}{\partial x}+v \frac{\partial T}{\partial y}\right)-\frac{u T}{\rho} \frac{\partial \rho}{\partial T} \frac{\partial P}{\partial x} \\
+k\left(\frac{\partial^{2} T}{\partial y^{2}}\right)+\mu\left(\frac{\partial u}{\partial y}\right)^{2}=0
\end{array}
$$

With boundary conditions:

$$
\begin{aligned}
& T=T_{o} \text { for } x \rightarrow-\infty \\
& k=k_{o}\left(1+10^{-4} \frac{P-P_{o}}{P_{o}}\right)
\end{aligned}
$$

With: $k_{o}=0.15 \mathrm{~W} / \mathrm{mK}$

\subsection{Oil Rheology}

The main oil type used is HLP46, mineral oil (DIN 51524-2). Dynamic viscosity and density at $T=40^{\circ} \mathrm{C}$ are $\mu=0.046$ Pa.s and $\rho=865 \mathrm{~kg} / \mathrm{m}^{3}$ respectively.

\subsubsection{Viscosity}

Viscosity considerably increases by increasing the pressure and decreases by increasing the temperature. The relationship govern this dependence is very important for accurate theoretical calculations. Physical constants used in this correlation are classified according to pressure level as low pressure region (up to 1000 bar) and high pressure region (over 1000 bar). Table 1 (appendix1) shows the constants of (17) at low and high pressure regions for the 3 oil types used. Oil groups are classified according to reference oil of the German research association of drives technology or in German Forschungsvereinigung Antriebstechnik (FVA). HLP46, mineral oil belongs to oil group FVA2 and oil type 28 [12].

$$
\begin{aligned}
& \ln \mu_{T, P}=\ln K_{p_{o}}+\frac{B_{p_{o}}}{T+C}+ \\
& P\left[\alpha_{T_{o}}+\frac{\Delta B}{\Delta P}\left(\frac{1}{T+C}-\frac{1}{T_{o}+C}\right)\right]
\end{aligned}
$$

With $C=95^{\circ} C, P_{o}=P_{a t m}$, and $T_{o}=0{ }^{\circ} C$ 


\subsubsection{Density}

Table 2 (appendix1) shows the constants of (18) at low and high pressure regions for the 3 oil types used [12].

$$
\rho_{T, P}=\rho_{o, o}+T \alpha_{T_{o}, 0 b a r}+P \alpha_{P, 0^{\circ} \mathrm{C}}+P T \frac{\Delta \alpha_{p}}{\Delta T}
$$

\subsection{Vane Tip Friction Force}

Friction between vane tip and cam-ring is assumed to be smooth contact friction due to oil shear only. The equations used are as follows:

$$
\begin{gathered}
\tau=\left.\mu \frac{\partial u}{\partial y}\right|_{\text {wall }} \\
\frac{d F_{f r}}{l_{\text {eff }}}=\tau d x+P d h \Leftrightarrow \frac{F_{f r}}{l_{\text {eff }}}=\int_{-\infty}^{\infty} \tau d x+\int_{-\infty}^{\infty} P \frac{d h}{d x} d x \\
\lambda=\frac{\left|F_{f r}\right|}{F}
\end{gathered}
$$

\subsection{Numerical Concept}

Numerical solution using finite difference technique was used. The lubricant film assumed to be parallel, so that the physical domain is rectangular, and there is no need to perform any transformations to computational domain, this will simplify the model. The pressure distribution along the $\mathrm{x}$-axis was taken according to Hertz (7). The mesh independent solution shows that, $60 \times 10$ points are sufficient. Table 3 (appendix1) shows the mesh independent results behavior.

\section{Validation of TEHL-Model}

Validation of TEHL-Model was tested by comparing computed results with experimental results [2]. The speed of $2000 \mathrm{rpm}(5 \mathrm{~m} / \mathrm{s})$ and oil temperature of $40^{\circ} \mathrm{C}$ were used. Fig. 3 shows the deviation behavior between TEHL-model and experimental results [2]. The deviation analysis show adequate good matching. The results error margin is kept below $10 \%$ for normal forces between $40 \mathrm{~N}$ and $110 \mathrm{~N}$. Within this margin, the simplified TEHL-model is sufficient to predict some parameters effect on the performance of the vane pump. This would offer a great support to vane pump designers in their primary decision making about their designs and oil type selection. Because experimental measurements were not available outside $120 \mathrm{~N}$, extending the TEHL-model margin of the normal vane force should be performed with great attention. Knowing that, increasing of vane tip speed would significantly reduce the vane friction coefficient while increasing of normal vane force would increase the friction with very low amount compared to velocity effect [2]. Based on this results normal vane force will be extended up to $200 \mathrm{~N}$ under a condition of using higher pump speed $(3500 \mathrm{rpm})$. This would guarantee effective performing of TEHL-model results with small deviation from experimental results.

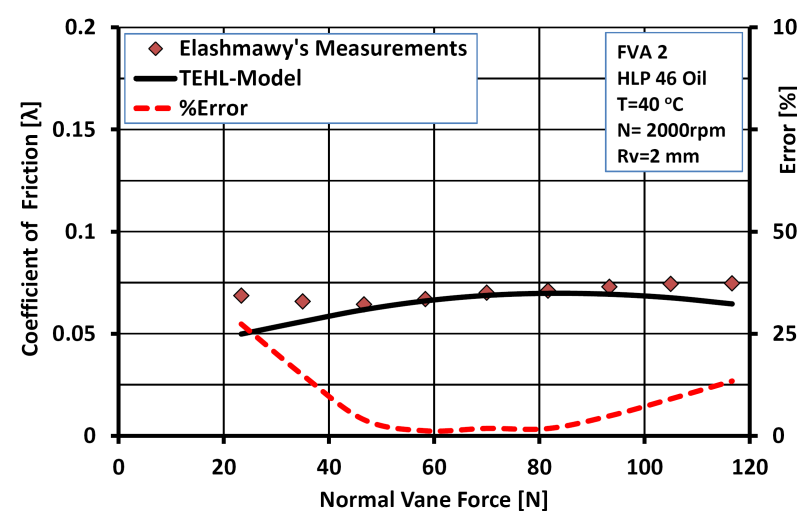

Figure 3. TEHL-model validation, deviation from experimental results at a speed of $2000 \mathrm{rpm}$.

\section{Results and Discussion}

\subsection{Effect of Operating Oil Temperature}

Effect of operating oil temperature on vane tip friction coefficient and oil film thickness is performed for 3 different oil groups (FVA1, FVA2 and FVA3). The comparison between the 3 oil groups was performed by plotting the 3 curves together on one graph. The speed of rotation of 3500 rpm was selected and the comparison was performed for two different normal vane forces ( $100 \mathrm{~N}$ and $200 \mathrm{~N})$. Fig. 4 shows the effect of operating oil temperature on vane tip friction coefficient at $3500 \mathrm{rpm}$ and $\mathrm{F}_{\mathrm{N}}=100 \mathrm{~N}$. The oil temperature strongly affects the friction coefficient. Increasing operating oil temperature increases coefficient of friction in the low temperature regions (almost below $70{ }^{\circ} \mathrm{C}$ ) while decreases it at high temperature regions (almost above $70^{\circ} \mathrm{C}$ ).

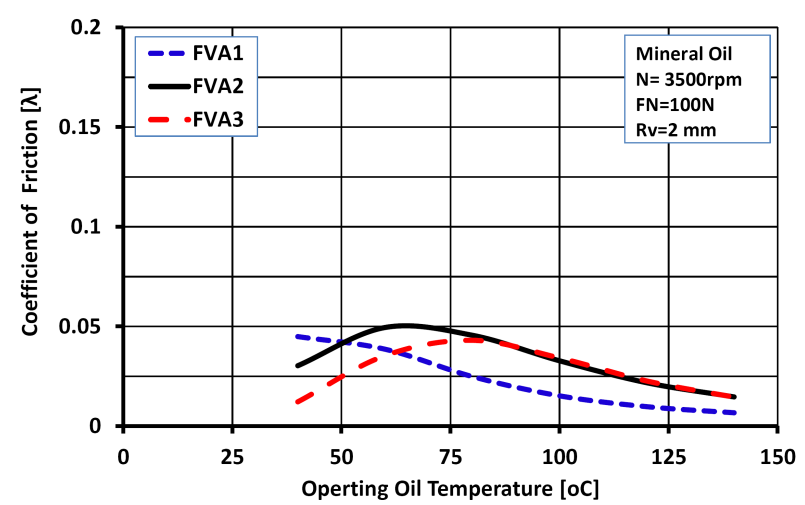

Figure 4. Effect of operating oil temperature on vane tip friction coefficient for 3 different oil groups, $F_{N}=100 N$.

Fig. 5 shows the effect of operating oil temperature on vane tip friction coefficient at $3500 \mathrm{rpm}$ and $F_{N}=200 \mathrm{~N}$. The oil temperature effect increases by increasing the normal vane force. The peak of the 3 curves was significantly shifted to the right. 


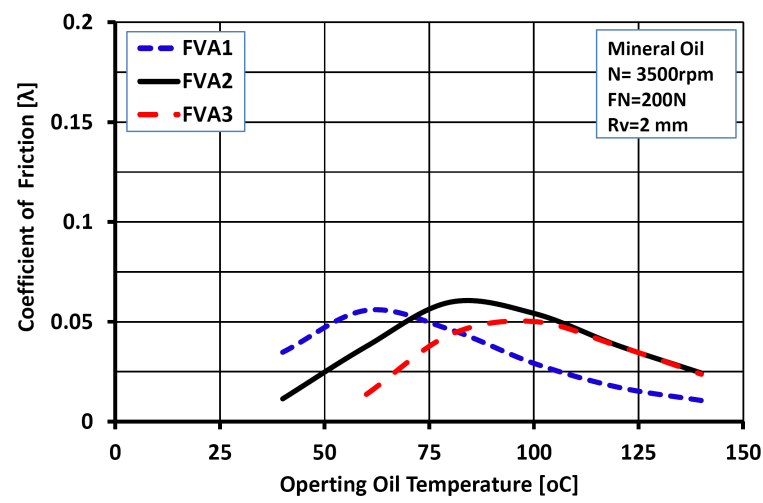

Figure 5. Effect of operating oil temperature on vane tip friction coefficient for 3 different oil groups, $F_{N}=200 N$.

Fig. 6 and Fig. 7 show the effect of operating oil temperature on oil film thickness for 3 different oil groups at two normal vane forces $(100 \mathrm{~N}$ and $200 \mathrm{~N})$. Increasing operating oil temperature significantly decreases the oil film thickness. The viscosity significantly decreases by increasing oil temperature which decreases the oil film thickness. It is clear from both curves of Figs. 6 and 7 that FVA3 oil group has the greatest oil film thickness compared to FVA2 and FVA1. However Figs. 4 and 5 show different behave of the three oil groups. Increasing oil film thickness alone is not sufficient to enhance friction conditions between vane tip and cam-ring, there are other important players engaged in this game.

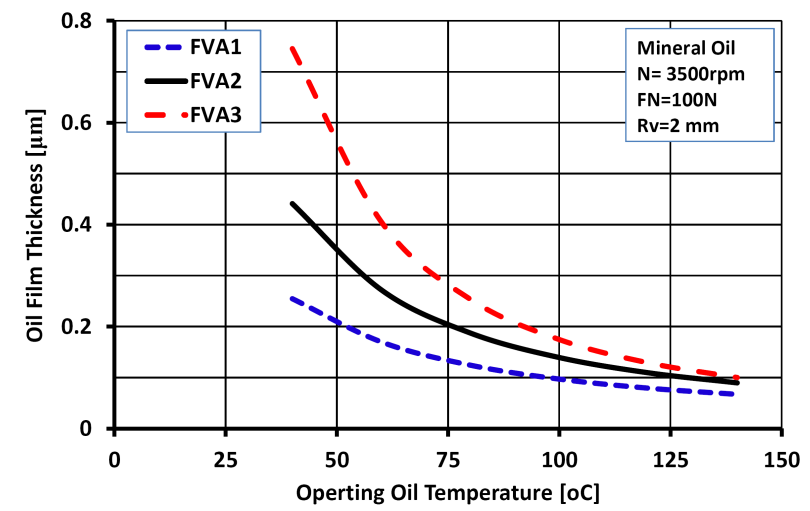

Figure 6. Effect of operating oil temperature on oil film thickness for 3 different oil groups, $F_{N}=100 N$.

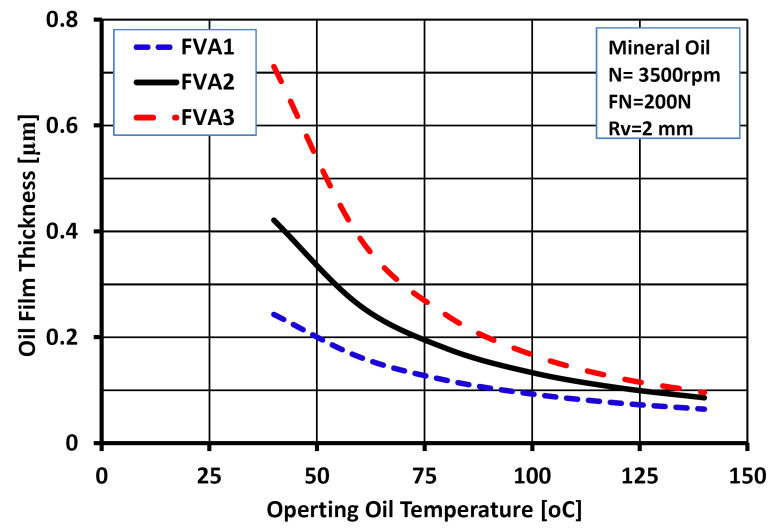

Figure 7. Effect of operating oil temperature on oil film thickness for 3 different oil groups, $F_{N}=200 N$.

\subsection{Effect of Rotational Speed}

Fig. 8 shows the effect of rotational speed on the vane tip friction coefficient for the 3 different oil types. The curves show significant rotational speed effect on the friction forces At high speed region, increasing speed of rotation significantly decreases the vane tip friction coefficient. The speed of rotation should not be less than $2000 \mathrm{rpm}(5 \mathrm{~m} / \mathrm{s})$ to guarantee good lubrication conditions. This result is in consistence with [2].

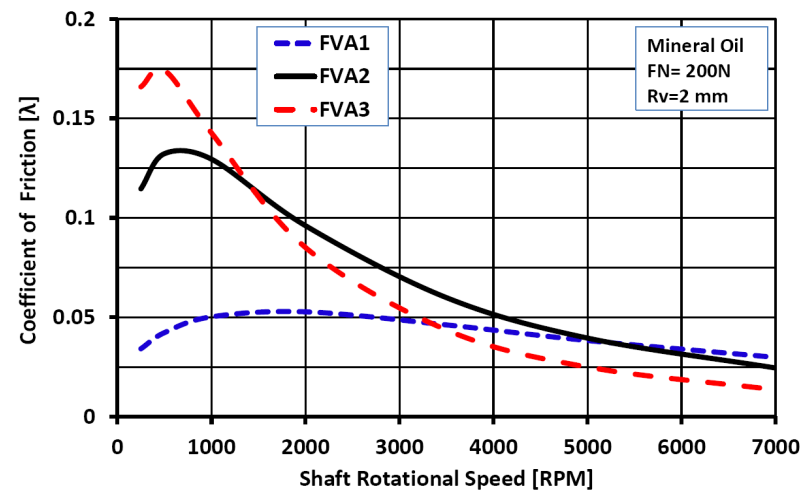

Figure 8. Effect of shaft rotational speed on vane tip friction coefficient for 3 different oil groups.

Fig. 9 shows the effect of shaft rotational speed on oil film thickness for 3 different oil groups. Increasing rotational speed increases significantly the oil film thickness. Although the highest oil film thickness was recorded for FVA3 oil group, it does not record the lowest friction coefficient at relatively low speed regions, see Fig. 8. So that depending only on enhancing oil film thickness is not sufficient to enhance friction conditions.

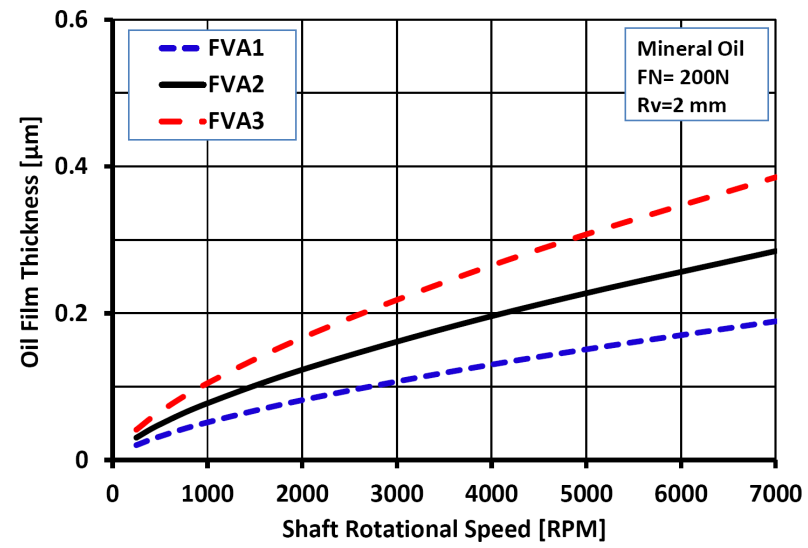

Figure 9. Effect of shaft rotational speed on oil film thickness for 3 different oil groups.

\subsection{Effect of Normal Vane Force}

Fig. 10 shows the effect of normal vane force on vane tip coefficient of friction for FVA2 oil group. Three different temperatures $\left(40,60\right.$ and $\left.80{ }^{\circ} \mathrm{C}\right)$ were used to predict the effect of oil temperature on the friction coefficient at a speed of $3500 \mathrm{rpm}$. Fig. 10 shows that increasing normal vane force increases vane friction coefficient at high temperature 
region $\left(80{ }^{\circ} \mathrm{C}\right)$. While at low temperature regions the opposite is almost true. The operating oil temperature is a key parameter for vane pump design. This because changing oil temperature changes significantly the oil properties.

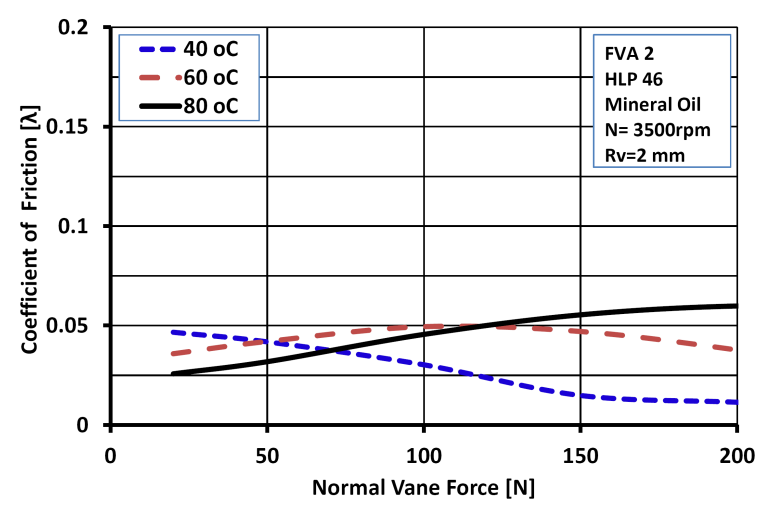

Figure 10. Effect of normal vane force on vane tip friction coefficient at 3500 rpm for FVA2 at 3 different temperatures.

Fig. 11 shows that FVA1 oil group has the lowest friction coefficient below the normal vane force of $200 \mathrm{~N}$, while it has the highest value above $270 \mathrm{~N}$. FVA3 shows the lowest friction coefficient value above $200 \mathrm{~N}$ of the normal force. The effect of normal vane force on friction coefficient is almost not much significant compared to vane speed or operating oil temperature parameters.

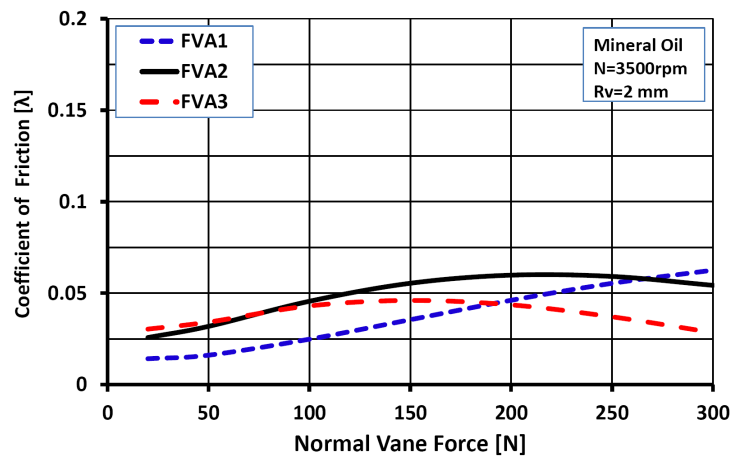

Figure 11. Effect of normal vane force on vane tip friction coefficient for 3 different oil groups.

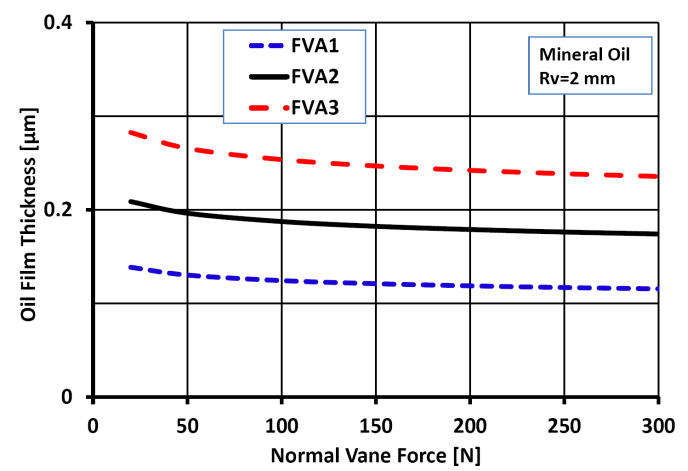

Figure 12. Effect of normal vane force on oil film thickness for 3 different oil groups.

Fig. 12 shows the effect of normal vane force on oil film thickness for 3 different oil groups. Increasing normal vane force decreases oil film thickness for all oil groups. Although FVA3 has the minimum oil film thickness, it has almost the lowest friction coefficient.

\section{Conclusions}

A simple TEHL-model was used to investigate the friction between vane tip and cam-ring in oil vane pumps. Three oil groups were theoretically investigated and their results were compared. Results show that relative speed between vane tip and cam-ring should be higher than $5 \mathrm{~m} / \mathrm{s}$ (2000 rpm) to keep friction at low values. Increasing of vane tip speed decreases significantly the friction between vane tip and cam-ring. Increasing oil film thickness alone does not guarantee the enhancement of friction conditions between vane tip and cam-ring in oil vane pumps. Operating oil temperature strongly affects the friction coefficient. Increasing operating oil temperature increases coefficient of friction in the low temperature regions while decreases it at the high temperature regions.

Suitable oil type for the vane pump in some conditions is not necessarily the best oil type choice for the same pump in other conditions. More than one oil type may be required to maximize vane pump performance when it runs in different conditions.

TEHL-model is not sufficient to predict vane tip friction coefficient in the boundary friction regions. More effort including material friction simultaneously with TEHL-model is needed for high load applications.

\section{Nomenclature}

$b_{H} \quad$ Hertzian deformation length $\quad[\mu \mathrm{m}]$

$c \quad$ Specific heat $\quad[\mathrm{J} / \mathrm{kgK}$

E Modulus of elasticity

$E^{\prime} \quad$ Effective modulus of elasticity

$[\mathrm{Pa}]$

$[\mathrm{Pa}]$

[N]

[N]

[--]

[ $\mu \mathrm{m}]$

[W/mK]

[W/mK]

[m]

[rpm]

[bar]

[bar]

$\left[\mathrm{W} / \mathrm{m}^{2}\right]$

[--]

[mm]

$\left[{ }^{\circ} \mathrm{C}\right]$

$\left[{ }^{\mathrm{o}} \mathrm{C}\right]$

$\left[{ }^{\circ} \mathrm{C}\right]$

$\left[{ }^{\mathrm{o}} \mathrm{C}\right]$

[--]

[m/s]

$[\mathrm{m} / \mathrm{s}]$

[--] 
$W_{V} \quad$ Vane width

Greek Symbols

$\lambda \quad$ Friction coefficient

$\mu \quad$ Dynamic viscosity

$v \quad$ Poisson's ratio, 0.3 for steel

$\rho \quad$ Density

$\tau \quad$ Shear stress [mm] Appendix 1

$[-]$

[Pa.s]

[--]

$\left[\mathrm{kg} / \mathrm{m}^{3}\right]$

$\left[\mathrm{N} / \mathrm{m}^{2}\right]$

Table 1. Constants of (17) at low and high pressures for the used oil groups [12]

\begin{tabular}{llllll}
\hline Pressure Range & $K_{P_{o}}[\mathbf{c p}]$ & $B_{P_{o}}\left[{ }^{\circ} \mathbf{C}\right]$ & $\alpha_{T_{o}}\left[\mathbf{1 0}{ }^{-3} / \mathbf{b a r}\right]$ & $\Delta B / \Delta P\left[{ }^{\circ} \mathbf{C} / \mathbf{b a r}\right]$ & Errror [\%] \\
\hline 11: FVA1 $\left(\mathrm{p} \leq 10^{3}\right)$ & 0.15330 & 621.53 & 2.6320 & 0.26817 & -- \\
11: FVA1 $\left(\mathrm{p}>10^{3}\right)$ & 0.0914 & 711.90 & 2.3609 & 0.26372 & 10.43 \\
28: FVA2 $\left(\mathrm{p} \leq 10^{3}\right)$ & 0.14393 & 754.49 & 3.0051 & 0.33613 & 1.150 \\
28: FVA2 $\left(\mathrm{p}>10^{3}\right)$ & 0.2397 & 720.79 & 2.8206 & 0.32838 & 4.55 \\
56: FVA3 $\left(\mathrm{p} \leq 10^{3}\right)$ & 0.07178 & 949.87 & 2.8751 & 0.27892 & 1.401 \\
56: FVA3 $\left(\mathrm{p}>10^{3}\right)$ & 0.1096 & 922.08 & 3.1316 & 0.37618 & 5.53 \\
\hline
\end{tabular}

Table 2. Constants of (18) at low and high pressures for the used oil groups [12]

\begin{tabular}{|c|c|c|c|c|c|}
\hline Pressure Range & $\rho_{o, o}$ & $\alpha_{T_{o}, \text { Obar }}\left[\mathbf{1 0}^{-4}\right]$ & $\alpha_{P, 0^{\circ} C}\left[\mathbf{1 0}^{-5}\right]$ & $\Delta \alpha_{p} / \Delta T\left[10^{-7}\right]$ & Error [\%] \\
\hline 11: FVA1 $\left(\mathrm{p} \leq 10^{3}\right)$ & 0.87008 & -6.4323 & 4.2719 & 1.1670 & 0.228 \\
\hline 11: FVA1 $\left(\mathrm{p}>10^{3}\right)$ & 0.8837 & -5.2660 & 2.7814 & 4.1137 & 1.12 \\
\hline 28: FVA2 $\left(\mathrm{p} \leq 10^{3}\right)$ & 0.88310 & -5.5440 & 4.2565 & 1.1010 & 0.246 \\
\hline 28: FVA2 $\left(\mathrm{p}>10^{3}\right)$ & 0.8986 & -5.7675 & 2.3967 & 0.984 & 1.13 \\
\hline 56: FVA3 $\left(\mathrm{p} \leq 10^{3}\right)$ & 0.89368 & -5.7325 & 4.5242 & 1.3220 & 0.266 \\
\hline 56: FVA3 $\left(\mathrm{p}>10^{3}\right)$ & 0.8953 & -2.9594 & 3.0319 & 1.000 & 1.00 \\
\hline
\end{tabular}

Table 3. Mesh size independent of numerical solution of TEHL-Model [1]

\begin{tabular}{lll}
\hline Grid Points & $\lambda$ & $\mathbf{T}_{\max } @ \mathbf{x} / \mathbf{b}_{\mathbf{H}}=\mathbf{0}$ \\
\hline 200 & 0.080 & 78.41 \\
300 & 0.081 & 78.46 \\
400 & 0.081 & 78.48 \\
500 & 0.082 & 78.48 \\
600 & 0.082 & 78.49 \\
700 & 0.082 & 78.49 \\
800 & 0.082 & 78.49 \\
\hline
\end{tabular}

\section{Appendix 2}

\section{Details of Vane Pump Geometry}

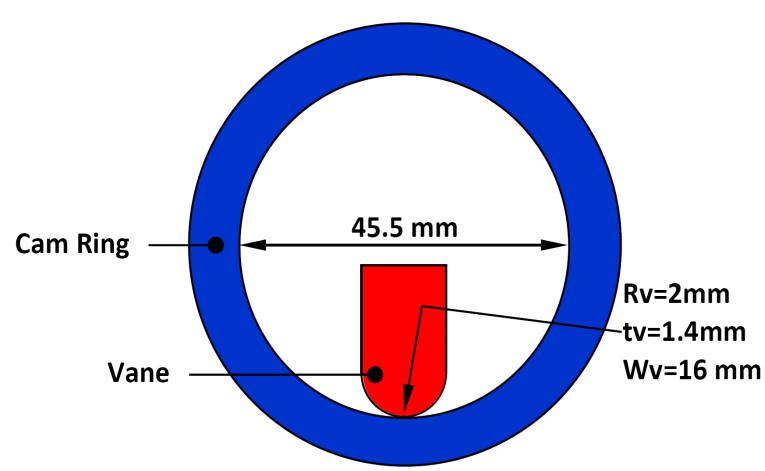

Figure 13. Geometry schematic diagram of the vane and cam-ring used for TEHL-model, exact dimensions.

\section{References}

[1] M. Elashmawy, "Study of Vane Tip Friction in Oil Vane pump," Suez Canal University Dissertation, Egypt, 2009.

[2] M. Elashmawy, and H. Murrenhoff, "Experimental Investigation of friction force between vane tip and cam-ring in oil vane pumps," International Journal of Fluid Power, Vol. 10, No. 1, pp 37-46, 2009.

[3] P. C. Sui, "Prediction of film thickness and friction at a rotary pump blade and liner interface," American Society of Mechanical Engineering (ASME), Vol. 72, ASME, New York, pp.115-122, 1995.

[4] M. Panek, "Vane pump control in order to maintain liquid friction and leak tightness," International Capathian Conference ICCC, Zakopane, Poland, 2004.

[5] Y. Inaguma, "Theoritical Analysis of Mechanical Efficiency in Vane Pump," JTEKT Engineering Journal English Edition, No. 1007E,; pp. 28-35, 2010.

[6] Y. Inaguma, and N. Yoshida, "Variation in Driving Torque and Vane Friction Torque in a Balanced Vane Pump," SAE Technical Paper, 2014-01-1764, 2014.

[7] Y. Inaguma, and A. Hibi, "Reduction of friction torque in vane pump by smoothing cam ring surface," Proceedings of the Institution of Mechanical Engineers Part C-Journal of Mechanical Engineering Science, 221 (5), pp. 527-534, 2007.

[8] H. M. Gabriel, et al., "Improved component performance of vane pumps by ion-plated TiN coatings," Elsevier, Thin Solid Films, 108 189-197, 1983. 
[9] Y. Inaguma, "Oil temperature influence on friction torque characteristics in hydraulic," Proc IMechE Part C: J Mechanical Engineering Science 226(9); pp. 2267-2280, 2011.

[10] Y. Inaguma and N. Yoshida, "Mathematical Analysis of Influence of Oil Temperature on Efficiencies in Hydraulic Pumps for Automatic Transmissions," SAE Int. J. Passeng. Cars - Mech. Syst. 6(2):786-797, doi:10.4271/2013-01-0820, 2013.
[11] P. W. Gold, "Tribology," Umdruck zur Vorlesung, Trans-Aix-Press, Aachen, Germany, 2003.

[12] J. Blume, "Druck und Temberatureinfluß auf Viscosität und Kompressibilität von flüssigen Schmierstoffen," RWTH Aachen University Dissertation, 1987. 